\title{
Utilização de um algoritmo genético híbrido para operação ótima de sistemas de abastecimento de água
}

Use of hybrid genetic algorithms for optimized operation of water supply systems

\author{
Luis Henrique Magalhães Costa \\ Engenheiro Civil. Doutor em Recursos Hídricos pela Universidade Federal do Ceará (UFC). \\ Marco Aurélio Holanda de Castro \\ Engenheiro Civil. PhD em engenharia. Professor Adjunto do Departamento de Engenharia Hidráulica de Ambiental da UFC \\ Helena Ramos \\ Engenheira Civil. PhD em engenharia. Professora do Instituto Superior Técnico de Lisboa
}

\begin{abstract}
Resumo
A operação dos Sistemas de Abastecimento de Água é realizada por profissionais que usam a sua experiência como um meio de avaliação no controle de equipamentos hidromecânicos com o objetivo de garantir o fornecimento de água à população. Geralmente, as regras operacionais utilizadas visam à garantia da continuidade do abastecimento público, sem a preocupação com a economia de energia elétrica dos motores em funcionamento. Neste trabalho, apresenta-se um algoritmo genético híbrido que permite determinar as estratégias de operações com custos energéticos reduzidos. A análise do modelo é feita em um estudo de caso real localizado na cidade de Ourém (Portugal). O novo modelo reduz consideravelmente o tempo computacional em comparação aos modelos utilizados na literatura especializada.
\end{abstract}

Palavras-chave: algoritmo genético híbrido, otimização, sistema de abastecimento de água.

\begin{abstract}
The operation of water supply systems is normally done by professionals who use their experience as the sole source of knowledge in order to establish rules to control the daily operation of hydro-mechanical equipments aiming at the guarantee of an adequate performance of the system. In general, these rules have as main goal the assurance of the water demands of the population and do not take into account optimization of the electrical energy consumed by the pumps. This work proposes a new hybrid genetic algorithm. The main purpose of this code is to determine optimized system operational rules with regard to saving electrical energy consumed by the pumps. The code was tested using one real water supply system localized in Ourém city (Portugal). The results showed considerable decrease in computational time as comparing to other codes available.
\end{abstract}

Keywords: hybrid genetic algorithm, optimization, water supply systems.

\section{Introdução}

Atualmente, é visível a preocupação do corpo científico mundial com a eficiência energética dos diversos setores de produção. Tal preocupação também se aplica ao setor operacional das empresas de saneamento. Segundo Tsutiya (2004), mais de 90\% dos gastos com energia elétrica das empresas de saneamento se devem às estações elevatórias de água e esgoto.

Pedrosa Filho (2006) afirma que, dentre os fatores que contribuem para esse elevado índice de consumo de energia, destacam-se: ausência de medição e monitoramento dos principais parâmetros que regulam o sistema; falta de um melhor compartilhamento dos dados entre várias gerências da companhia; equipamentos antigos e ultrapassados; envelhecimento das tubulações; elevado desperdício de água utilizável; falta de uma política de manutenção e substituição; complexidade das redes de condutos e má política de gerenciamento operacional dos grupos elevatórios e falta de investimentos na área operacional.

Dentre as medidas práticas que podem levar à redução do custo de energia elétrica, a alteração dos procedimentos operacionais de bombeamento demonstra ser bastante eficaz, pois não necessita de nenhum investimento e, além disso, a economia, devido a essa 
redução, ocorre em curto prazo. Entretanto, a determinação de estratégias operacionais que gerem custos energéticos reduzidos e que mantenham a qualidade do atendimento aos clientes é uma tarefa complexa. Objetivos distintos estão envolvidos neste processo como, por exemplo, a utilização eficiente da tarifa energética e a manutenção das variáveis hidráulicas dentro dos limites pré-estabelecidos. É necessária a utilização de modelos que levem em consideração todos esses elementos envolvidos.

Com os avanços tecnológicos na área computacional e, consequentemente, o desenvolvimento de técnicas de otimização, inúmeros trabalhos visando à redução do custo energético de operação de Sistema de Abastecimento de Água (SAA) têm sido divulgados nos últimos anos. Entretanto, a maioria dos modelos desenvolvidos foi aplicada a casos específicos.

Os primeiros trabalhos envolvendo a otimização do custo energético de bombeamento utilizaram-se de técnicas de pesquisa operacional como, por exemplo, programação linear (JOWITT; GERMANOPOULOS, 1992; BURNELL; RACE; EVANS, 1993), programação linear inteira (LITTLE; MCCRODDEN, 1989), programação não-linear (CHASE; ORMSBEE, 1993; YU; POWELL; STERLING, 1994) e programação dinâmica (STERLING; COULBECK, 1975; LANSEY; AWUMAH, 1994). A limitação da utilização desses modelos em casos reais se deve principalmente à complexidade das resoluções das equações que garantem o equilíbrio hidráulico da rede, à dificuldade de generalizar tais modelos de otimização em qualquer SAA e à tendência de demandar um tempo computacional excessivo.

Ainda assim, Brion e Mays (1991), na tentativa de reduzir os custos operacionais em um SAA para Austin, Texas (EUA), testaram um modelo de otimização e simulação, conseguindo, com uma política otimizada de bombeamento, uma redução de 17,3\% do custo operacional que vinha sendo realizado até então. Ormsbee e Reddy (1995) aplicaram um algoritmo de otimização em Washington (DC) e obtiveram uma economia considerável com a política fornecida pelo modelo, observando uma redução de 6,9\% nos custos com energia elétrica. Nesse período, a utilização de algoritmos evolucionários era limitada. Wood e Reddy (1994) foram um dos pioneiros na utilização de tais algoritmos para a redução do custo energético em sistemas elevatórios. Para tanto, acoplaram um simulador hidráulico a um modelo de otimização baseado em algoritmos genéticos.

Nos últimos anos, inúmeros trabalhos foram desenvolvidos no Brasil sobre o tema deste estudo, utilizando o algoritmo genético (AG) como principal ferramenta do modelo de otimização (RIGHETTO, 2002; FORMIGA, et al, 2003; CARRIJO, 2004; PEDROSA FILHO, 2006). Tal fato se deve ao fato de o AG propiciar uma grande flexibilidade na exploração do espaço de busca e permitir facilmente sua conectividade com modelos de simulação.

Entretanto, o AG não trata diretamente problemas com restrições. É necessária a utilização de outros métodos para contornar essa limitação. Como a operação em SAA é considerada um problema complexo, com muitas restrições, resta dúvida quanto à velocidade de modelos que considerem a junção entre o AG padrão e simuladores hidráulicos na convergência e definição da solução ótima.

Nesse contexto, um conjunto de trabalhos foi publicado numa edição especial do Journal of Hydroinformatics (MARTINEZ, et al, 2007; JAMIESON, et al, 2007; SALOMONS et al, 2007; RAO; ALVARRUIZ, 2007; RAO; SALOMONS, 2007; ALVISI; FRANCHINI; MARINELLI, 2007). Para reduzir o tempo computacional demandando na busca de soluções com custo energético reduzido, esses autores utilizaram a técnica de Redes Neurais Artificiais (RNA) para replicar os resultados gerados pelo simulador hidráulico EPANET (ROSSMAN, 2000). Em seguida, conectaram o novo modelo de simulação hidráulica ao AG. Após análises feitas em um sistema hipotético e dois estudos de casos reais, os autores chegaram à conclusão que o modelo AG-RNA encontrou ótimas soluções em um período 20 vezes inferior quando comparado ao AG-EPANET. Já Shamir e Salomons (2008), objetivando reduzir o tempo computacional, criaram um modelo reduzido de um estudo de caso real.

A preocupação com a redução do tempo computacional se deve à aplicabilidade de modelos de otimização energética em tempo real.

O atual consenso sobre a importância da elaboração de planos e metas que levem em consideração a eficiência energética em setores com grandes demandas de energia foi o motivador para o desenvolvimento deste trabalho, no qual, em vez de se tentar reduzir o tempo computacional na etapa de simulação hidráulica, apostou-se na redução do tempo computacional com a alteração do AG padrão. Para tanto, foram criados novos algoritmos que atuam diretamente sobre as soluções infactíveis geradas pelo AG na tentativa de torná-las factíveis, desenvolvendo-se, assim, um algoritmo genético híbrido (AGH) (algoritmos reparadores + operadores genéticos).

O modelo determina, em intervalos discretos (a cada hora), a melhor programação a ser seguida pelas bombas (ligada/desligada) para um horizonte diário de operação. Dessa forma, as decisões de efetuar manobras passam a ser orientadas a partir da pesquisa de milhares de combinações possíveis, sendo escolhida, por meio de um processo iterativo, a estratégia que apresentar menor valor do custo energético diário.

Este trabalho foi estruturado em cinco pontos. Após a introdução, é realizada uma breve abordagem na formulação da operação de SAA. No terceiro ponto, propõe-se a junção entre o AG, o EPANET e os algoritmos reparadores. Em seguida, no quarto ponto, descrevese o estudo de caso utilizado para a avaliação do modelo e, por fim, apresentam-se as conclusões.

\section{Formulação do modelo}

A busca pela operação ótima de bombas em um SAA real é encarada como um problema de elevada complexidade pelo fato de 
envolver um grande número de variáveis de decisão e muitas restrições próprias de cada sistema. As variáveis de decisão são os estados operacionais das bombas $\mathrm{x}_{\mathrm{t}}\left(\mathrm{x}_{1 \mathrm{t}}, \mathrm{x}_{2 \mathrm{t}}, \ldots \mathrm{x}_{\mathrm{Nt}}\right)$, onde $\mathrm{N}$ representa o número de bombas e t o passo de tempo ao longo do horizonte operacional.

Para representar os estados das variáveis de decisão em cada passo de tempo, utilizou-se a notação binária. A configuração da bomba pode ser representada por um bit. Para bombas com velocidades variáveis, é necessária a utilização de mais de um bit, pois, nesta situação, não ocorre apenas os estados ligado/desligado.

O objetivo principal do modelo é encontrar o status de funcionamento de bombas que resulte no menor custo energético possível no horizonte operacional. Entretanto, para o cálculo desse custo, inúmeras variáveis intermediárias devem ser consideradas em cada passo de tempo, como, por exemplo, a variações dos consumos, custos tarifários e estados das bombas.

A função objetivo representa o custo da energia consumida pelas $\mathrm{N}$ bombas durante os $\mathrm{T}$ intervalos de tempo em que o horizonte de planejamento diário foi subdividido. Pode ser expressa de acordo com a equação:

$\operatorname{Min} C E=\sum_{n=1}^{N} \sum_{t=1}^{24} C_{n t} \times E_{n t}\left(X_{n t}\right)$

Equação 1

Sendo: E e C representam a energia consumida (kWh) e o custo tarifário ( $\$ / \mathrm{kWh})$ da bomba n e passo de tempo t, respectivamente.

A cada avaliação das soluções, a primeira restrição a ser avaliada é implícita. Essa restrição é constituída pelas equações da continuidade em cada nó e da conservação de energia em cada anel da rede. Essas equações estão implícitas no cálculo da função objetivo e precisam ser resolvidas para que se obtenha o custo energético total da solução a ser analisada. Esses procedimentos são desempenhados pelo simulador hidráulico EPANET.

Após a etapa supracitada, alguns parâmetros são verificados, visando a avaliar o desempenho hidráulico da solução analisada. Essa avaliação é feita considerando-se limites pré-estabelecidos. As restrições explícitas representam tais limites e também podem ser associadas ao conceito de confiabilidade hidráulica do sistema. Tais restrições são descritas e equacionadas a seguir.

A definição de estratégias ótimas de operação em SAA, que consiste em avaliar o comportamento do sistema e tomar decisões a cada passo de tempo, requer uma grande demanda computacional. Dentre os vários métodos de otimização disponíveis, o algoritmo genético (AG) foi a metodologia escolhida por oferecer uma grande flexibilidade na exploração do espaço de busca, aliado à possibilidade do uso de variáveis discretas. Além disso, a técnica é de fácil manipulação, o que facilita a sua conectividade com modelos de simulação.

O modelo é composto por dois módulos que trabalharão em conjunto, de forma que a rotina de simulação hidráulica seja chamada para simular cada alternativa operacional gerada pelo AG na busca de alternativas de melhor desempenho.

Além da utilização de um algoritmo genético simples (AGS), também é analisada a utilização de um algoritmo genético híbrido (AGH). Esse algoritmo foi construído através da união de um AGS com um método de correção de soluções. A finalidade é encontrar mais rapidamente soluções factíveis, difíceis de serem encontradas por algoritmos genéticos tradicionais devido ao alto índice de aleatoriedade provocados pelos operadores genéticos.

\section{Algoritmo genético - EPANET \\ Algoritmo genético simples (AGS)}

O AG é um método estocástico de busca global realizada através da evolução de uma população de soluções. O princípio de funcionamento, difundido por Goldberg (1989), é baseado na analogia biológica da teoria da evolução e da seleção natural de populações.

$\mathrm{Na}$ operação de SAA, o AG se destaca por ser bastante eficiente quando são utilizadas variáveis discretas e binárias, além de apresentar um conjunto de soluções ótimas e não uma única solução. A cada nova geração, soluções contendo os estados dos elementos hidráulicos (bombas/válvulas) são avaliadas e, posteriormente, classificadas conforme sua aptidão. A tendência deste processo é de que com o decorrer das iterações de AGs (gerações), as piores soluções (indivíduos menos adaptados ao meio, em termos biológicos) desapareçam e, em contrapartida, sejam criadas outras soluções (indivíduos, em termos biológicos) mais bem ajustadas às restrições (imposições, em termos biológicos) do problema.

O AG, como toda ferramenta de busca direta, não trata diretamente os problemas de otimização que contêm funções restritivas. Este impedimento nos modelos de minimização pode ser contornado empregando-se o Método de Penalidades, segundo o qual as restrições existentes em cada solução são adicionadas à função objetivo em termos de penalidades, tornando a solução menos apta tanto quanto forem suas violações das restrições. O Método da Penalidade Multiplicativa (MPM), apresentado por Hilton e Culver (2000) é utilizado no modelo. A Figura 1 ilustra o procedimento AGS-EPANET para seleção de regras operacionais ótimas.

A primeira etapa do processo caracteriza-se pela geração de regras operacionais, definição de demandas e custo tarifário. Em seguida, estas variáveis são utilizadas pelo EPANET que, por sua vez, calcula as pressões nos nós, a energia consumida e os níveis dos reservatórios, variáveis necessárias para a avaliação da solução. A etapa seguinte caracteriza-se pelo cálculo da função objetivo, expressa em termos do custo energético total, e da função penalidade, caso a solução seja inviável. O processo é repetido até que sejam obtidos parâmetros de controle operacional que atendam às solicitações hidráulicas com um custo menor possível. 


\section{Algoritmo genético híbrido (AGH)}

O algoritmo genético simples (AGS) utilizado no modelo faz uso do método das penalidades, transformando as soluções infactíveis em soluções de aptidão reduzida. Os operadores genéticos apenas diversificam as soluções, porém não as tornam factíveis. Neste caso, pode-se afirmar que o processo de busca de soluções hidraulicamente factíveis, com custos energéticos mínimos, é fortemente estocástico.

No processo de avaliação da função objetivo, as variáveis restritivas explícitas (por exemplo, pressões nodais, níveis dos reservatórios - Tabela 1) podem ser avaliadas a cada hora. Dessa forma, nesse intervalo de tempo, é possível verificar os tipos de restrições que foram violados. Diante disto, foram criados algoritmos de correções de soluções que, a cada hora, tentam "corrigir" as soluções geradas pelo AG, tornando-as hidraulicamente factíveis. O novo layout do modelo é apresentado na Figura 1.

Tabela 1 - Restrições explícitas

\begin{tabular}{|ll}
\hline Restrições & Limites \\
\hline Pressões nos nós & $\begin{array}{l}\text { Pressões dos nós entre os limites mínimos } \\
\text { e máximos }\end{array}$ \\
\hline Níveis dos reservatórios I & $\begin{array}{l}\text { Níveis dos reservatórios entre os limites } \\
\text { mínimos e máximos }\end{array}$ \\
\hline Níveis dos reservatórios II & $\begin{array}{l}\text { Os níveis dos reservatórios no fim do } \\
\text { horizonte operacional (24h) devem ser } \\
\text { superiores aos níveis iniciais (Oh) }\end{array}$ \\
\hline Potência das bombas & $\begin{array}{l}\text { A potência de cada bomba deve ser inferior } \\
\text { à potência máxima permitida }\end{array}$ \\
\hline $\begin{array}{l}\text { Quantidade de } \\
\text { acionamento nas bombas }\end{array}$ & $\begin{array}{l}\text { ao longo do dia deve ser inferior a um limite } \\
\text { pré-estabelecido }\end{array}$ \\
\hline
\end{tabular}

Cada solução gerada pelo AG é repassada aos algoritmos de correções. Após esta etapa, são consideradas duas soluções: a solução original (indivíduo 1 - Figura 1), gerada pelo AG, e a solução modificada (indivíduo 2 - Figura 1), gerada após as tentativas de correções. As soluções com funções penalidades nulas (soluções factíveis) são enviadas a um banco de dados (população paralela). Independentemente do destino da solução modificada, a solução original será conservada e enviada às próximas gerações do AG, evitando-se uma convergência prematura das soluções.

Os algoritmos de correção são um conjunto de regras que modificam as variáveis de decisão, objetivando tornar as soluções hidraulicamente factíveis a cada hora (Figura 2).

Dentre as formas de correções apresentadas na Figura 2, aquela relacionada ao número máximo de acionamentos é a única que não utiliza as rotinas do EPANET. Este é o primeiro tipo de reparação que ocorre nas soluções factíveis e tem como objetivo principal a redução da quantidade de acionamentos, alterando-se o mínimo possível da configuração original da solução. A Figura 3 ilustra esse tipo de reparação para uma solução de uma bomba com seis acionamentos.

No exemplo da Figura 3, com apenas quatro alterações, foi possível reduzir de seis para dois a quantidade de acionamentos da solução. Além da redução considerável da quantidade de acionamentos, também é possível observar na solução reparada uma maior uniformidade dos horários em que a bomba encontra-se ligada. A solução alterada passou a ter apenas dois períodos com a bomba em funcionamento. A utilização da bomba em longos períodos é característica das estratégias comumente utilizadas em sistemas reais devido à menor intervenção na operação e redução no desgaste das bombas. 


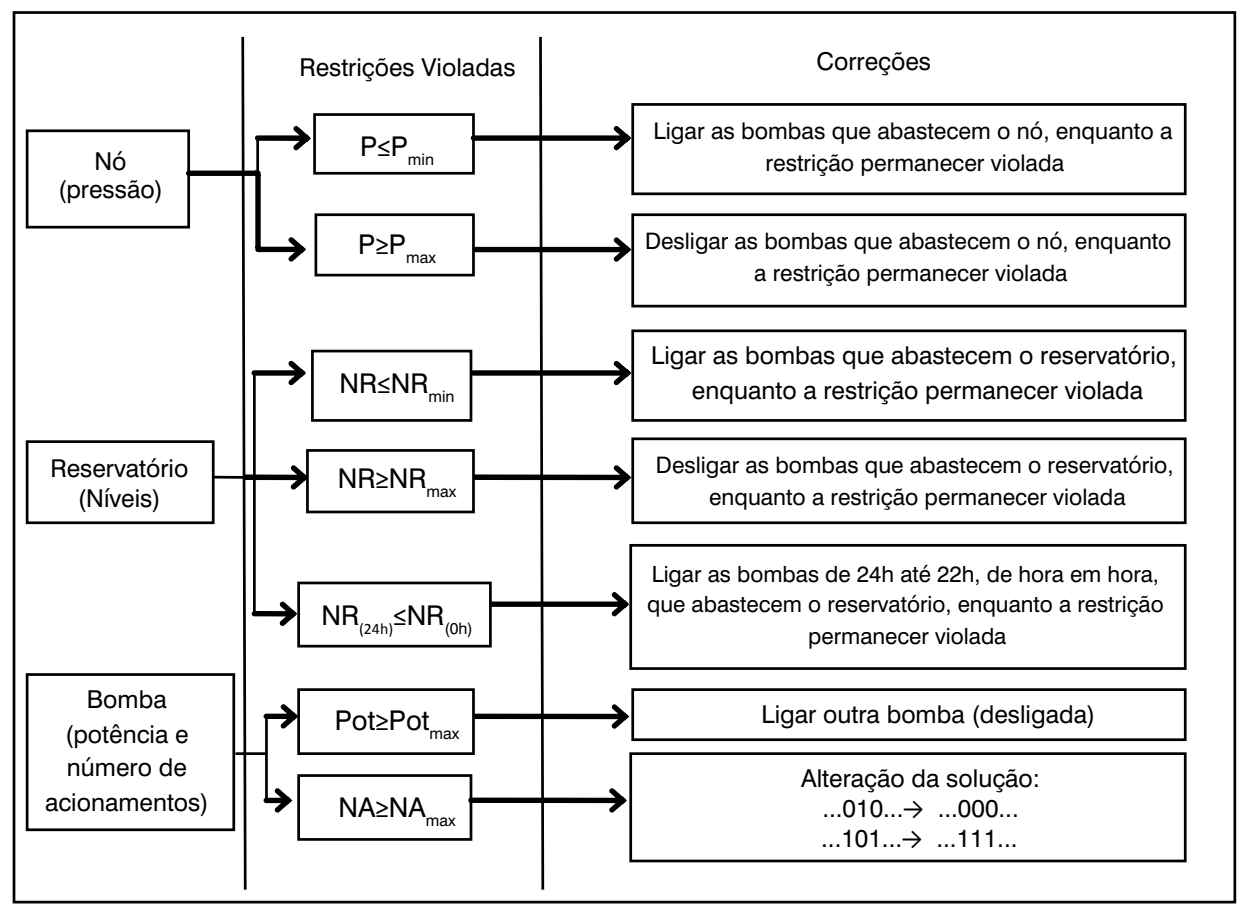

Figura 2 - Tipos de algoritmos de correções

Os demais algoritmos de correções procuram, a cada hora, corrigir as soluções com restrições violadas. A cada tentativa de correção, o EPANET é chamado para que se possa verificar se a solução tornou-se viável ou não. Um exemplo contendo a reparação relativa à potência máxima das bombas em um sistema com quatro bombas, de uma mesma estação elevatória, é apresentado na Figura 4.

No exemplo apresentado, supõe-se que sejam permitidos até três acionamentos por dia. Na tentativa de corrigir esta solução, procurase ligar outra bomba no mesmo horário (10h) cuja restrição da potência máxima foi violada. Para tanto, procuram-se as bombas com menores quantidades de acionamentos (bombas 3 e 4) e, dentre essas, primeiramente liga-se aquela em que uma possível alteração não resultará em um novo acionamento (bomba 3). Caso o problema não seja resolvido, as outras bombas desse conjunto são ligadas, uma a uma, até solucionar o problema.

A regra de preferência de acionamento das bombas ora citada também é utilizada pelos algoritmos de reparação que atuam nas inviabilidades geradas pelos reservatórios e nós. A utilização dessa regra guia esses algoritmos de forma a evitar que as alterações das soluções não violem a restrição de acionamento máximo por bombas. Além disto, com essa regra, aumenta-se a possibilidade de alterações viáveis nas horas seguintes do dia.

Devido à quantidade de intervenções realizadas nas soluções infactíveis, não é possível determinar o número de vezes que o EPANET é chamado a cada solução inviável encontrada, pois ao corrigir uma solução devido a um tipo de restrição, possivelmente outros tipos de

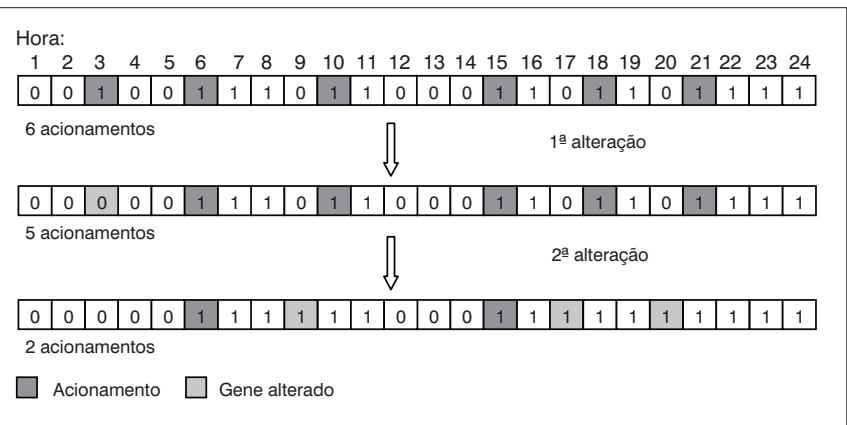

Figura 3 - Aplicação da reparação relativa à quantidade de acionamentos por bomba

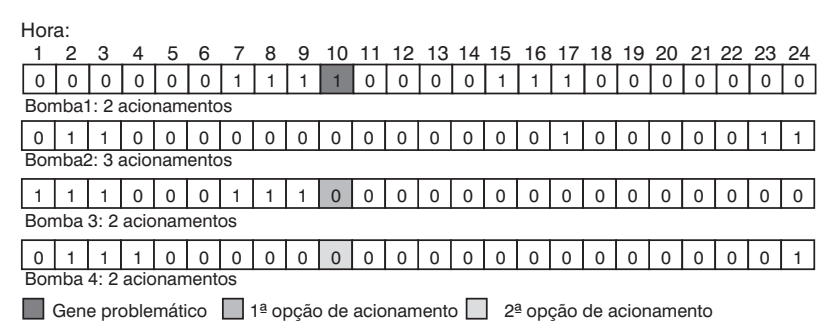

Figura 4 - Aplicação da reparação relativa à potência máxima por bombas

restrições que até então estavam violadas podem passar a manter-se dentro de seus limites pré-estabelecidos. Por exemplo: em uma solução infactível observou-se que às 7 h o nível e a pressão de um reservatório e um nó atingiram valores superiores aos limites máximos. Ao 
tentar corrigir a solução (i.e. desligando uma bomba às 7h) devido à restrição relativa ao nível do reservatório, provavelmente a pressão no nó ora citado poderá assumir um valor inferior ao seu limite máximo. Além disso, é possível que essa correção (desligamento da bomba) solucione problemas com restrições de horas posteriores à sétima hora. Contudo, pode-se comparar os algoritmos de correções à mutação, sendo que no primeiro as alterações (0-1 ou 1-0) são feitas de forma direcionada, eliminando-se o aspecto aleatório da mutação.

Já para o SGA, o procedimento é mais simples e rápido. A cada solução inviável, o EPANET é chamado apenas uma vez, objetivando verificar as restrições violadas e, em seguida, calcular as penalidades que serão aplicadas à função objetivo. O tempo computacional de cada iteração utilizado pelo SGA é inferior quando comparado ao HGA. Entretanto, a quantidade de iterações necessárias à obtenção de boas soluções é o principal fator no tempo total estimado para se obterem boas soluções.

Para tornar o AGH aplicável a SAAs com mais de uma estação elevatória, foi necessário o desenvolvimento de um algoritmo de análise de sensibilidade hidráulica. Tal algoritmo determina a influência de cada bomba sobre os nós restritivos e reservatórios. Para identificar quais reservatórios são abastecidos por cada bomba, é realizado o seguinte procedimento: tornam-se nulas as demandas de todos os nós e, em seguida, ligam-se as bombas, uma a uma, verificando-se os reservatórios que tiverem seus níveis alterados. Aqueles que não tiveram seus níveis alterados não são abastecidos pela bomba que foi ligada. Já para determinar a influência das bombas nos nós restritivos, primeiramente fecham-se todos os trechos à montante e jusante de todos os reservatórios. Posteriormente, ligam-se as bombas de forma semelhante ao procedimento ora citado e verificam-se os nós que tiveram pressões acrescidas. Esta análise é importante, pois em situações com mais de uma estação elevatória, como no estudo de caso apresentado no decorrer deste trabalho, é necessário identificar qual(is) possível(is) bomba(s) resolveria(m) o problema da violação de restrições de determinado reservatório ou nó.

A determinação dos operadores genéticos tem forte influência no processo de convergência do Algoritmo Genético. A definição desses

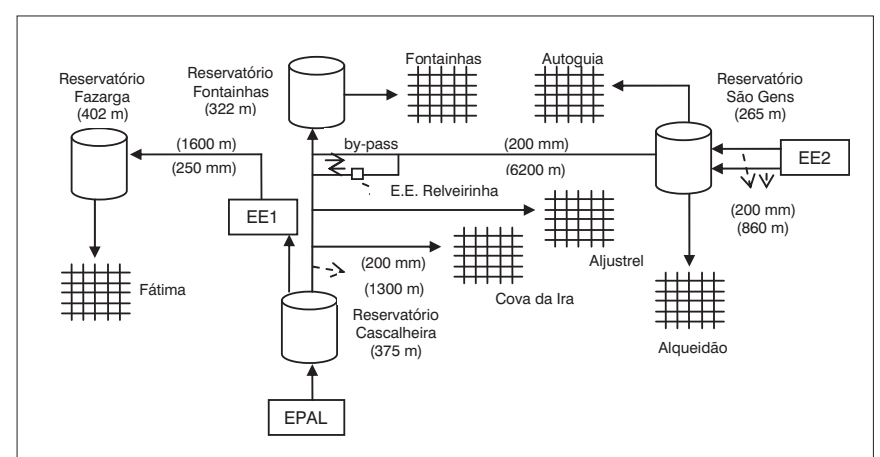

Figura 5 - Esquema do abastecimento e distribuição dos reservatórios Fazarga e São Gens parâmetros é função da natureza e complexidade do problema de otimização em foco. De acordo com Goldberg (1989), aumenta-se o desempenho do AG combinando uma alta probabilidade de cruzamento com uma baixa probabilidade de mutação e com um tamanho de população moderado. Os parâmetros de entrada utilizados no estudo de caso são os mesmos adotados por Pedrosa Filho (2006) que, para o mesmo tipo de problema, concluiu que os melhores valores são: probabilidade de cruzamento de 0,7; probabilidade de mutação de 0,009 e tamanho da população de 100 indivíduos (soluções). Vale ressaltar que a definição desses parâmetros varia de problema para problema.

O tipo de seleção escolhido foi o torneio $(n=2)$ por sua maior simplicidade de implementação quando comparado aos demais tipos, enquanto o tipo de cruzamento utilizado foi o uniforme. Utilizou-se, ainda, na evolução das iterações, o procedimento elitista na taxa de 1\%, ou seja, é mantida a melhor solução de cada iteração.

Por fim, vale ressaltar que o algoritmo genético foi desenvolvido na linguagem Pascal (Delphi), e todas as análises deste trabalho foram feitas em um computador com processador AMD Athlon X2 1.58Ghz, com 1.87GB RAM.

\section{Estudo de caso}

O sistema adutor de Ourém foi utilizado para o propósito deste estudo. Ele é composto por 22 captações, 10 estações de tratamento, 36 estações elevatórias e 64 reservatórios. A água é distribuída aos consumidores ao longo de $1.111 \mathrm{~km}$ de rede de distribuição e adução. Atualmente, o sistema é gerenciado pela empresa Veolia Água - Águas de Ourém que é responsável pela captação, tratamento e distribuição da água. Por meio do sistema de telegestão desta empresa, todos os dados necessários ao desenvolvimento do presente estudo de caso foram disponibilizados.

De todo o SAA de Ourém, dois subsistemas adutores foram escolhidos. O primeiro abastece o reservatório Fazarga com cota de soleira de $402 \mathrm{~m}$. Este reservatório é responsável pelo atendimento às demandas da região de Fátima e outras localidades adjacentes. Essa adução é feita por meio de uma estação elevatória (EE1) localizada nas proximidades do reservatório Cascalheira (cota de soleira de $375 \mathrm{~m}$ ). Este último é abastecido pela EPAL (Empresa Portuguesa das Águas Livres) e fornece, por gravidade, água às localidades de Aljustrel e Cova da Ira e ao reservatório Fontainhas.

O segundo subsistema adutor utilizado na otimização é formado por outra estação elevatória (EE2) que abastece o reservatório de São Gens (cota: $267 \mathrm{~m}$ ) a partir de uma fonte de água na localidade de Caridade, (cota 152,0 m). Por sua vez, aquele reservatório abastece as localidades de Autoguia e Alqueidão (Figura 5). Ambas as estações elevatórias são providas de quatro bombas, com bombas do tipo Grundfos NK 65-250 e Caprari HV 65/2C, respectivamente.

Conforme citado anteriormente, o abastecimento de água do reservatório Cascalheira é feito pela EPAL. O custo gerado à Veolia 
por este fornecimento está relacionado somente com o volume de água efluente deste reservatório e não depende de qualquer alteração na operação da estação elevatória da adutora entre os reservatórios Cascalheira e Fazarga. A redução deste custo somente seria possível com a diminuição do consumo nos pontos de demanda ou com a implementação de políticas de redução de perdas de água por vazamento. O nível do reservatório Cascalheira é mantido sempre próximo ao seu limite máximo de forma a aumentar a confiabilidade do sistema. Desta forma, no modelo de otimização, na elevatória Cascalheira/Fazarga, optou-se por considerar somente a variação do nível do reservatório Fazarga que, por sua vez, encontra-se à jusante da EE1.

O contrato celebrado entre a Veolia e a EPAL prevê um volume anual fixo de água a ser fornecido ao reservatório Cascalheira. Geralmente ao final do mês de novembro de cada ano, faz-se um balanço desse volume. Caso seja constatado que o volume de água já fornecido esteja próximo daquele pré-estabelecido, o reservatório de Cascalheira será abastecido também pelo reservatório São Gens por meio da estação elevatória de Relveirinha, objetivando reduzir a oferta de água da EPAL. Se ao invés disso, houver uma grande disponibilidade de água ainda a ser fornecida, o fluxo de água se dará no sentido do reservatório Cascalheira para o São Gens, por gravidade. O transporte de água direto entre esses reservatórios não foi considerado no modelo por ser uma estratégia operacional atípica.

O reservatório de Cascalheira tem capacidade de armazenar $4.000 \mathrm{~m}^{3}$ de água enquanto o Fazarga possui um volume total de $347 \mathrm{~m}^{3}$ e opera com os níveis inicial, mínimo e máximo de 2,0 m, 0,3 m e 2,3 m, respectivamente. Por sua vez, o reservatório São Gens possui um volume máximo de $328,9 \mathrm{~m}^{3}$. Os níveis inicial, máximo e mínimo são 3,61 m, 3,8 m e 0,3 m.

A variação horária dos consumos nas regiões de Fátima (21.31L/s), Autoguia (8.81L/s) e Alqueidão (1.1L/s) ao longo do dia foi obtida a partir de sensores de vazão localizados na saída dos reservatórios (Fazarga e São Gens). O período analisado foi de julho a setembro de 2007. O consumo de água neste período do ano é mais acentuado por abranger o período do verão (Figura 6).

A modelagem de SAA requer a representação do sistema real da maneira mais fidedigna possível para que se possa reproduzir o comportamento do mesmo. Desta forma, para utilização do modelo de simulação hidráulica estendida, é necessária a realização dos seguintes passos: coleta de dados, construção do modelo no EPANET e calibração do mesmo. Para a calibração do SAA analisado, escolheuse uma data (12/07/2007) em que as bombas mantiveram-se ligadas em intervalos semelhantes ao formato (discretos a cada hora) considerado no modelo de otimização. Em seguida, a operação realizada neste dia foi simulada no EPANET. A variação dos níveis reais dos reservatórios (Fazarga e São Gens) e aquela calculada pelo EPANET demonstrou-se bastante semelhante, propiciando credibilidade nas respostas apresentadas por esse simulador.
O custo unitário de energia, em unidades monetárias por kWh, foi considerado em conformidade com as tarifas cobradas pela empresa concessionária de energia elétrica EDP (Energias de Portugal) para o ano de 2007. Inseridos todos os parâmetros necessários (como tarifas energética, restrições hidráulicas), os modelos de otimização foram aplicados, produzindo os resultados apresentados a seguir.

Objetivando uma melhor visualização dos gráficos, abstraiu-se destes a parte referente às soluções infactíveis. Assim, na Figura 7 observase que as ordenadas representam apenas o custo energético, sem as penalidades. Observa-se a superioridade do AGH em relação ao AGS. Este último identificou a primeira solução factível (€44,89), das 18 encontradas, aos 126,68 minutos e a solução final (€41,10) aos 157,7 minutos. Para o AGH, que contou com 52 soluções viáveis, esses valores são, respectivamente, ( $€ 44,22)$ aos 12,23 minutos e $(€ 39,76)$ aos 28,86 minutos. Isto representou uma economia de $16 \%$ para o AGH e 13\% para o AGS, levando em consideração que o custo energético da operação realizada (27/07/2007) pela Veolia foi de €47,29.

As Figuras 8, 9, 10 e 11 contêm as estratégias operacionais de ambas as estações elevatórias para ambos os modelos de otimização.

A solução final obtida pelo AGH não utilizou a bomba em nenhum período cuja tarifa horária fosse mais elevada. Já o AGS manteve a bomba em funcionamento nesse período em apenas uma hora na EE1. Podem-se considerar as soluções econômicas obtidas pelos

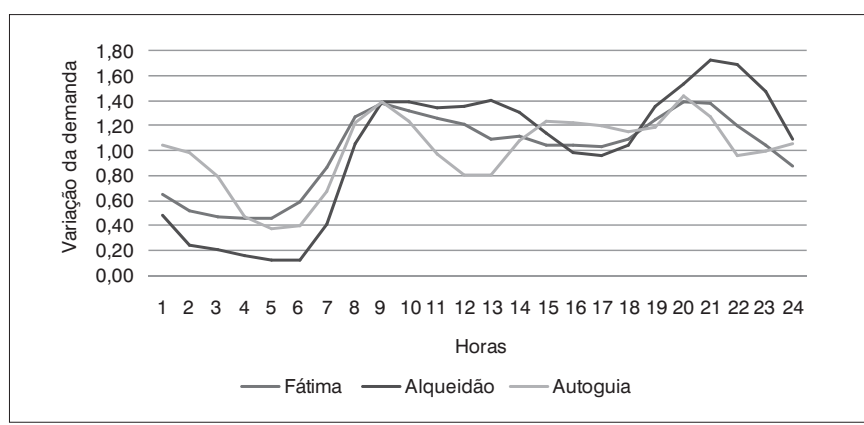

Figura 6 - Variação da demanda para as localidades de Fátima, Alqueidão e Autoguia

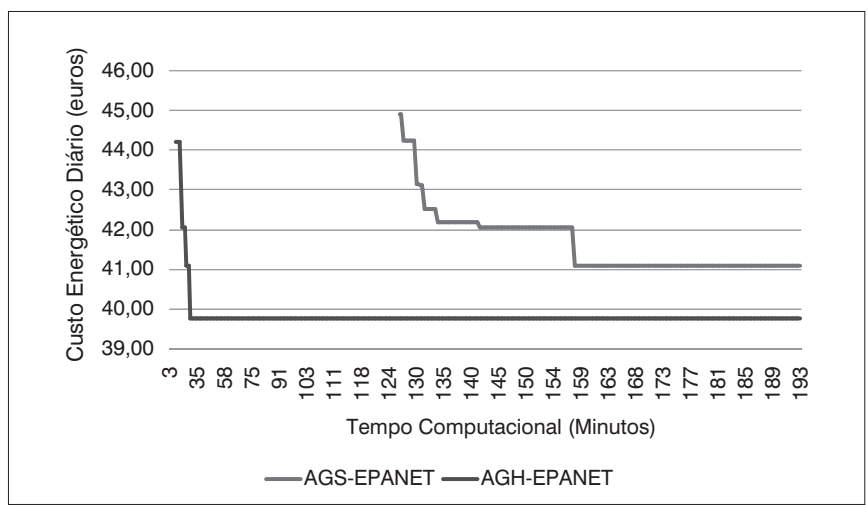

Figura 7 - Evolução do custo energético com o tempo de processamento computacional (AGH e AGS) 


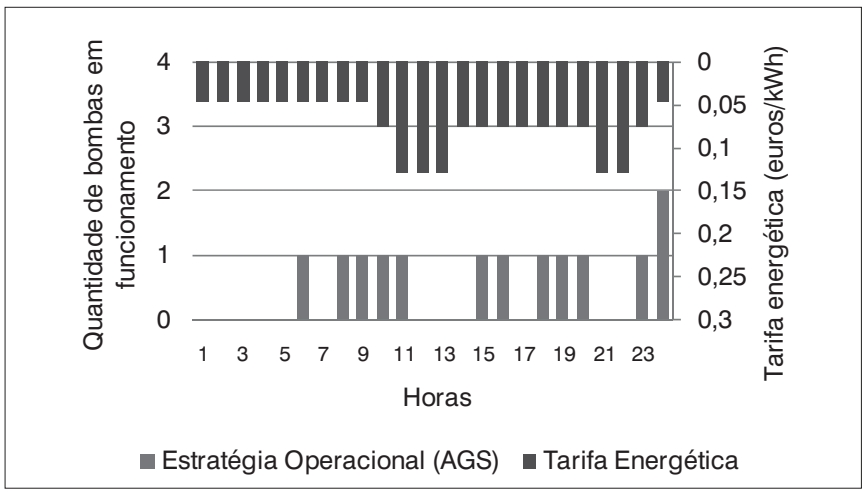

Figura 8 - Solução final (EE1 - AGS)

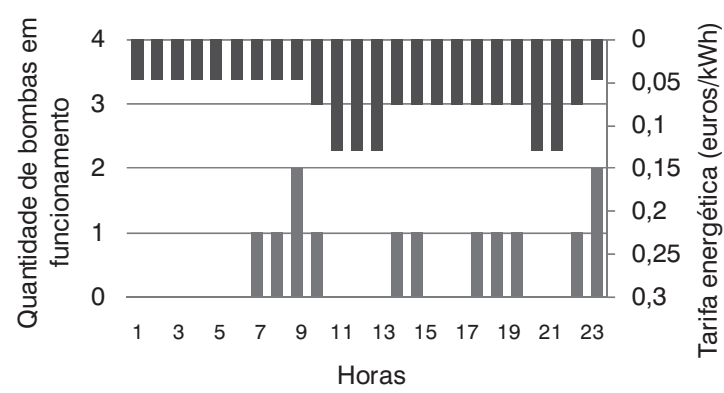

Estratégia Operacional (AGH) — Tarifa Energética

Figura 9 - Solução final (EE1 - AGH)

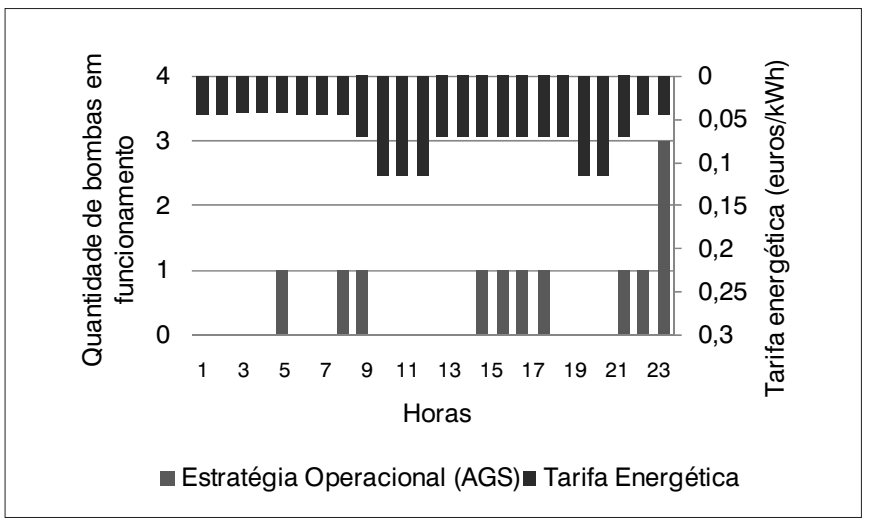

Figura 10 - Solução final (EE2 - AGS)

algoritmos mais "ousadas", ou seja, com os valores das variáveis de estado (por exemplo, níveis dos reservatórios) mais próximos de seus limites. Na Figura 12, é possível observar este comportamento.

Os algoritmos de otimização aproveitam bem as diferenças das tarifas horárias, ligando as bombas nos horários que precedem as tarifas mais elevadas, visando ao aumento dos níveis dos reservatórios de forma que, nesse período, o abastecimento se dê por gravidade. Em contrapartida, ainda pela Figura 12, é possível verificar que, após o período de tarifa mais elevada, os níveis dos reservatórios se aproximam de seus

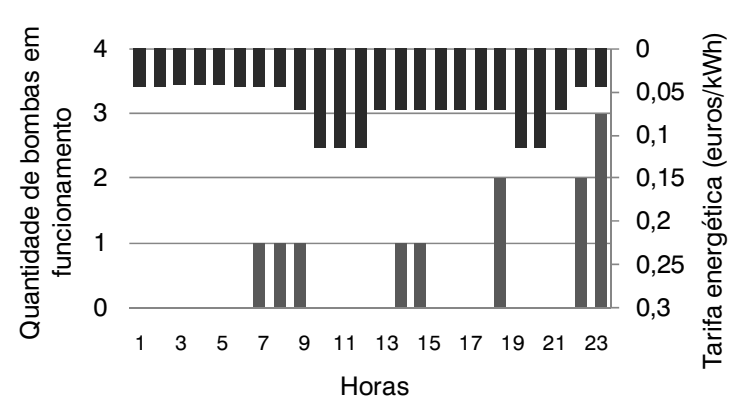

- Estratégia Operacional (AGH) — Tarifa Energética

Figura 11 - Solução final (EE2 - AGH)

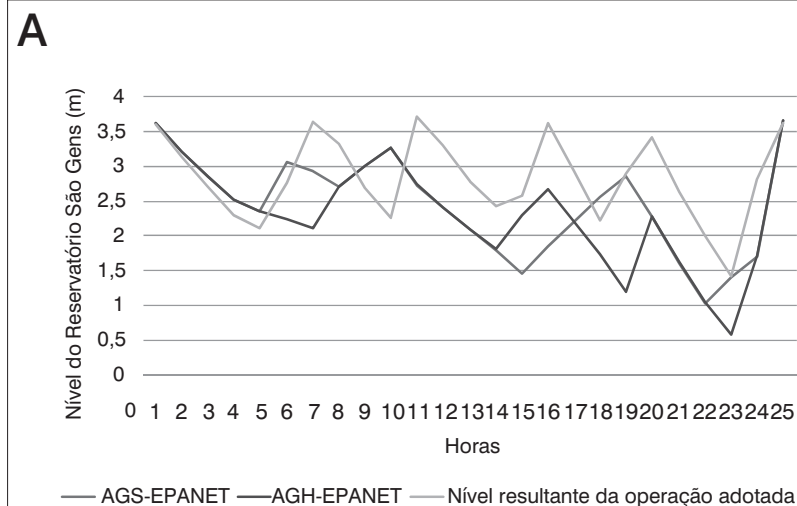

B

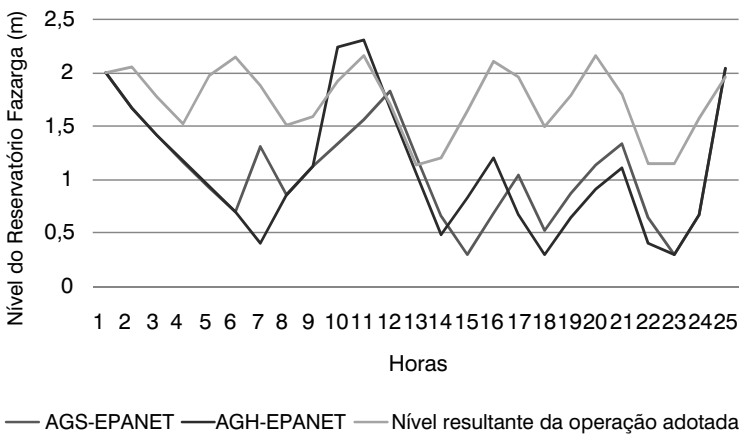

Figura 12 - Variação dos níveis dos reservatórios São Gens (A) e Fazarga (B) ao longo do dia

níveis mínimos para as soluções otimizadas. Esta redução mais brusca ocorre às $22 \mathrm{~h}$ para o reservatório São Gens e às $23 \mathrm{~h}$ para o reservatório Fazarga. Por fim, pode-se observar que os níveis dos reservatórios ao fim do dia (24h) foram superiores aos do início da operação (Oh).

Apesar de a Veolia adotar os níveis mínimos para seus reservatórios de 0,3 m, na operação do dia selecionado, esses valores foram todos superiores a $1 \mathrm{~m}$, aumentando sua confiabilidade hidráulica.

Em relação aos modelos de otimização avaliados, nota-se claramente a maior eficiência dos resultados encontrados pelo AGH. As 
alterações das soluções ao longo das gerações feitas pelo AGS são feitas inteiramente por processos aleatórios (operadores genéticos: seleção, cruzamento e mutação). Dentre esses, somente o cruzamento e a mutação são responsáveis pela alteração genética das soluções. No cruzamento, ocorre a troca de material genético entre os indivíduos. Entretanto, essa troca não garante que os genes dos indivíduos problemáticos (soluções inviáveis) sejam alterados. Já a mutação, ocorre alteração dos genes dos indivíduos sem nenhum critério. No AGH, a cada iteração, verificam-se as restrições que foram violadas e associam-se tais violações aos seus genes. Esses genes "problemáticos" são alterados com o objetivo de tornar as restrições invioladas. Por isto, observa-se a maior eficiência (quantidade de soluções viáveis encontradas) e rapidez do AGH em comparação ao AGS.

A identificação dos genes "problemáticos" somente é possível em razão da quantidade de funções que a ferramenta Toolkit do EPANET disponibiliza. Dessa forma, os níveis dos reservatórios e pressões dos nós podem ser analisados em cada passo de cálculo realizado por esse simulador. Devido à forma como as soluções são alteradas pelos algoritmos de correções, tais algoritmos podem ser comparados a um tipo de mutação induzida.

\section{Conclusões}

Neste trabalho, explorou-se a viabilidade da utilização de um AGH na busca pela estratégia operacional de menor custo energético para um SAA real localizado na cidade de Ourém, em Portugal.

Para tanto, novos algoritmos de correções foram desenvolvidos e introduzidos ao AG padrão. Com esses algoritmos, a partir de uma análise feita nas soluções inviáveis geradas pelo AG, alteraram-se as variáveis de decisão na tentativa de torná-las soluções factíveis.

O AGH se diferencia do algoritmo genético padrão e de outros métodos de busca, pois utiliza as restrições dos sistemas para gerar e melhorar suas soluções, de modo que, em cada iteração, uma melhoria é garantida, não somente uma evolução totalmente randômica.

Para o estudo de caso analisado, o modelo AGH-EPANET convergiu cinco vezes mais rapidamente quando comparado ao AGS-EPANET. Isso confirma a eficiência dos algoritmos criados na busca da solução de melhor custo operacional de uma rede. Acredita-se que quanto mais complexa for a rede, mais vantajosa será a utilização do modelo criado devido à dificuldade que o AGS tem em encontrar soluções viáveis.

Considerando que, em poucas gerações, com auxílio dos algoritmos desenvolvidos, o modelo obteve grande êxito, é interessante realizar uma avaliação sobre a necessidade da utilização dos operadores genéticos. Provavelmente, se estes algoritmos forem aplicados diretamente a um grande conjunto de soluções geradas aleatoriamente, também chegariam a ótimos resultados. Além disso, devido à rapidez com que o algoritmo identifica boas soluções, também é interessante uma averiguação sobre a aplicação do modelo criado em otimização em tempo real.

Com o uso do algoritmo de análise de sensibilidade hidráulica, é possível determinar os nós e reservatórios que são influenciados por cada bomba. A utilização desse algoritmo possibilita o uso dos algoritmos de reparação em SAAs com mais de uma estação elevatória. Dessa forma, afirma-se que o modelo apresentado neste trabalho pode ser utilizado em qualquer rede criada no EPANET, facilitando sua utilização por estudantes, pesquisadores e profissionais da área.

\section{Agradecimentos}

A CAPES (Coordenação de Aperfeiçoamento de Pessoal de Nível Superior) pela bolsa de estudos concedida no Brasil e em Lisboa.

A Veolia e, principalmente, aos engenheiros Sylvain Arabeyre e Nuno Marques pela cessão dos dados utilizados e pelas discussões operacionais.

\section{Referências}

ALVISI, S.; FRANCHINI, M.; MARINELLI, A. A short-term, pattern-based water demand-forecasting model. Journal of Hydroinformatics, v. 9, n. 1, p. $39-50,2007$

BRION, L.M.; MAYS, L.W. Methodology for optimal operation of pumping stations in water distribution systems. Journal of Hydraulic Engineering ASCE, v. 117, n. 11, p. 1551-1569, 1991

BURNELL, D.; RACE, J.; EVANS, P. Overview of the trunk scheduling system for the London Ring Main. Water science and Technology, v. 28, n. 11-12, p. 99-109, 1993

CARRIJO, I.B. Extração de regras operacionais ótimas de sistemas de distribuição de água através de algoritmos genéticos multiobjetivo e aprendizado de máquina. Tese (Doutorado em Engenharia) - Escola de Engenharia de São Carlos da USP, São Carlos, 2004.

CHASE, D.V.; ORMSBEE, L.E. Computer-generated pumping schedules for satisfying operating objectives. Journal AWWA, v. 85, n. 7, p. 54-61, 1993.

FORMIGA, K.T.M. et al. Optimal design of water distribution system by multiobjective evolutionary methods. 2nd EVOLUTIONARY MULTICRITERION OPTIMIZATION INTERNATIONAL CONFERENCE, Faro, Portugal, 2003.

GOLDBERG, D.E. Genetic algorithm is search optimization and machine learning. Boston: Addison-Wesley Longman Publishing Co. Inc., 1989 
HILTON, A.B.C.; CULVER, T.B. Constraint handling for genetic algorithms in optimal remediation design. Journal of Water Resources Planning and Management, ASCE, v. 126, n. 3, p. 128-137, 2000.

JAMIESON, D.G. et al. Conceptual design of a generic, real-time, near-optimal control system for water-distribution networks. Journal of Hydroinformatics, v. 9, n. 1, p. 3-14, 2007.

JOWITT, P.W. GERMANOPOULOS, G. Optimal pump scheduling in watersupply networks. Journal of Water Resources Planning and Management, ASCE, v. 110, n. 1, p. 17-35, 1992.

LANSEY, K.E.; AWUHMAH, K. Optimal pump operations considering pump switches. Journal of Water Resources Planning and Management, ASCE, v. 110, n. 1, p. 17-35, 1994.

LITTLE, K.W.; McCRODDEN, B.J. Minimization of Raw Water Pumping Cost Using MILP. Journal of Water Resources Planning and Management, ASCE, v. 115, n. 4, p. 511-522, 1989.

MARTINEZ, F. et al. Optimizing of the operation of the Valencia waterdistribution network. Journal of Hydroinformatics, v. 9, n. 1, p. 65-78.2, 2007.

ORMSBEE, L.E.; REDDY, S.L. Nonlinear heuristic for pump operations. Journal of Water Resources Planning and Management, ASCE. v. 121, n. 4, p. 302-309, 1995

PEDROSA FILHO, L. Um modelo de operação de sistemas adutores de abastecimento de água com vistas a minimização dos custos energéticos. Tese (Doutorado em Recursos Naturais) - Universidade Federal de Campina Grande, Campina Grande, Paraíba, 2006.

RAO, Z.; ALVARRUIZ, F. Use of an artificial neural network to capture the domain knowledge of a conventional hydraulic simulation model. Journal of Hydroinformatics, v. 9, n. 1, p. 15-24, 2007.
RAO, Z.; SALOMONS, E. Development of a real-time, near-optimal control system for water-distribution networks. Journal of Hydroinformatics, v. 9 n. 1, p. 25-38, 2007.

RIGHETTO, A.M. Operação ótima de sistema urbano de distribuição de água. In: Seminário - Planejamento, Projeto e Operação de Redes de Abastecimento de Água: o estado da arte e questões avançadas, João Pessoa, PB, 2002.

ROSSMAN, L.A. EPANET User's Manual. Cincinnati: US Environmental Protection Agency, 2000

SALOMONS, E. et al. Optimizing the operation of the Haifa-A waterdistribution network. Journal of Hydroinformatics, v. 9, n. 1, p. 51-64, 2007.

SHAMIR, U.; SALOMONS, E. Optimal real-time operation of urban water distribution systems using reduced models. Journal of Water Resources Planning and Management, ASCE, v. 134, n. 2, p. 181-185, 2008.

STERLING, M.J.H.; COULBECK, B. A dynamic programming solution to the optimization of pumping costs. ICE Proceedings, London, v. 59, n. 2, p. 813-818, 1975

TSUTIYA, M. T. Abastecimento de Água. 2a edição. São Paulo: Departamento de Engenharia Hidráulica e Sanitária da USP, 2004.

WOOD, D.J.; REDDY, L.S. Control de Bombas de Velocidad Variable y Modelos en Tiempo Real para Minimizar Fugas y Costes Energéticos. In: CABRERA, E.; VELA, A.F. Mejora del Rendimiento y de la Fiabilidad en Sistemas de Distribución de Agua. Valência, Espanha: Universidad Politécnica de Valencia, Universitat Jaume I de Castellón, 1994, p.173-207.

YU, G.; POWELL, R.S.; STERLING, M.J.H. Optimized pump scheduling in water distribution systems. Journal of Optimization Theory and Application, v. 83, n. 3, p. 463-488, 1994. 